\title{
Tooth chipping patterns in Paranthropus do not support regular hard food mastication
}

\author{
Ian Towle ${ }^{\mathrm{a}}$, Joel D. Irish ${ }^{\mathrm{b}, \mathrm{c}}$, Carolina Loch ${ }^{\mathrm{a}}$ \\ a Sir John Walsh Research Institute, Faculty of Dentistry, University of Otago, Dunedin 9054, \\ New Zealand \\ ${ }^{\mathrm{b}}$ Research Centre in Evolutionary Anthropology and Palaeoecology, School of Biological and \\ Environmental Sciences, Liverpool John Moores University, United Kingdom, L3 3AF \\ ${ }^{\mathrm{C}}$ Evolutionary Studies Institute and Centre for Excellence in PaleoSciences, University of the \\ Witwatersrand, Private Bag 3, WITS 2050, South Africa
}

\section{Corresponding author.}

Email address: ian.towle@otago.ac.nz (I. Towle) 


\begin{abstract}
The paranthropines, including Paranthropus boisei and Paranthropus robustus, have often been considered hard-food specialists. The large post-canine teeth, thick enamel, and robust craniofacial features are often suggested to have evolved to cope with habitual mastication of hard foods. Yet, direct evidence for Paranthropus feeding behaviour often challenges these morphological interpretations. The main exception being antemortem tooth chipping which is still regularly used as evidence of habitual mastication of hard foods in this genus. In this study, data were compiled from the literature for six hominin species (including P. boisei and P. robustus) and 17 extant primate species, to analyse Paranthropus chipping patterns in a broad comparative framework. Severity of fractures, position on the dentition, and overall prevalence were compared among species. The results indicate that both Paranthropus species had a lower prevalence of tooth fractures compared to other fossil hominin species (P. boisei: 4\%; P. robustus: 11\%; Homo naledi: 37\%; Australopithecus africanus: 17\%; Homo neanderthalensis: 45\%; Epipalaeolithic Homo sapiens: 29\%); instead, their frequencies are similar to apes that masticate hard items in a non-regular frequency, including chimpanzees, gibbons, and gorillas (4\%, $7 \%$ and $9 \%$ respectively). The prevalence is several times lower than in extant primates known to habitually consume hard items, such as sakis, mandrills, and sooty mangabeys (ranging from $28 \%$ to $48 \%$ ). Comparative chipping analysis suggests that both Paranthropus species were unlikely habitual hard object eaters, at least compared to living durophage analogues.
\end{abstract}

Key words: Enamel fractures; Paranthropus robustus; Paranthropus boisei; hominin diet; Durophagy 


\section{Introduction}

When a tooth contacts a hard object with enough force, the enamel can break and fracture to create a chip (Chai and Lawn, 2007; Constantino et al., 2010). The fractured area can vary depending on mechanical and structural properties of the enamel and object (Thomas, 2000; Constantino et al., 2010; He and Swain, 2008; Lawn, Lee, Constantino, and Lucas, 2009; Scott and Winn, 2011). Chips are not generated through a gradual process, although cumulative effects related to enamel fatigue and demineralization may contribute to fracture likelihood and location (Gao et al., 2016; Sanchez-Gonzalez et al., 2020). Importantly, it can take many years of subsequent wear to erase evidence of a chip, making them a crucial marker of past behavior and diet (Belcastro et al., 2018; Towle et al., 2017; Constantino, Markham, and Lucas, 2012).

Enamel chips can be caused by a variety of factors, including food processing, environmental contaminants (e.g., sand or grit), dietary items and social behavior (Constantino et al., 2012; Sauther, Sussman, and Cuozzo, 2002; Scott and Winn, 2011; Stojanowski, Johnson, Paul, and Carver2015; Van Valkenburgh, 2009). These different influences can generate unique chipping patterns across the dentition, and allow inferences of dietary and behavioral factors in archaeological and paleoanthropological samples (Belcastro et al., 2007; Constantino et al., 2010; Scott and Winn, 2011; Nystrom, PhillipsConroy, and Jolly, 2004; Towle et al., 2017). A range of recent human populations, fossil hominins and extant primates have been studied for evidence of chipping (e.g., Belcastro et al., 2007; Bonfiglioli et al., 2004; Gould, 1968; Lous, 1970; Molnar et al., 1972; Silva, Gil, Soares, and da Silva, 2016; Turner and Cadien, 1969; Constantino et al., 2010; Grine et al., 2010; Robinson, 1954; Tobias, 1967; Johanson and Taieb, 1976; Ward et al., 2001; Fox and Frayer, 1997; Scott and Winn, 2011; Stojanowski et al., 2015; Larsen, 2015; Lous, 1970; Molnar et al., 1972; Fannin et al., 2020). However, until recently, differences in recording methods have made inter-study comparisons challenging.

Enamel chipping may provide critical insights into the feeding habits of enigmatic hominins, such as the 'robust Australopith' clade, e.g., Paranthropus boisei and P. robustus. Paranthropus species have long been inferred to be hard object feeders (durophagous), with large bunodont posterior teeth and robust cranial features thought to reflect adaptations related to habitually masticating hard foods (Rak, 1983; Jolly, 1970; Teaford and 
Ungar, 2000; Constantino et al., 2018). However, the diets of these species are still debated, with a variety of dietary scenarios described (e.g., Martínez et al., 2016; Williams, 2015; Strait et al., 2013; Smith et al., 2015; Cerling et al., 2011; Van der Merwe et al., 2008; Wood and Strait, 2004). Additionally, there is often an apparent disconnect between diet and craniodental morphology in Paranthropus.

Direct evidence from enamel microwear studies of $P$. boisei suggests little to no hard object feeding (Ungar et al., 2008). In P. robustus, higher enamel surface complexity may indicate hard foods were consumed more frequently (Ungar, 2019; Scott et al., 2005; Peterson et al., 2018), potentially in the context of 'fallback foods'. However, the role of hard plant tissues in generating microwear features is currently debated (van Casteren et al., 2020; Teaford et al., 2020). From stable carbon isotopes, the diets of $P$. robustus and $P$. boisei appear substantially different (Cerling et al., 2011; Ungar and Sponheimer, 2011). Isotopic results for $P$. boisei are in concordance with microwear and some biomechanical evidence, suggesting that hard foods such as seeds and nuts did not make up a significant part of their diet; rather, C4 graminoids (e.g., grasses and sedges) were likely common food sources (Guatelli-Steinberg, 2016; Macho, 2014; Dominy et al., 2008; Yeakel et al., 2007; Cerling et al., 2011; Kaiser et al., 2019). A more recent study on comparative biomechanical and morphological data in primates also suggests a soft-food niche for Paranthropus (Marcé-Nogué et al., 2020). Based on this and other evidence, many dental anthropologists now regard Paranthropus as non-hard food eaters (Ungar and Hlusko, 2016; Grine and Daegling, 2017; Kaiser et al., 2019), while others consider them dietary generalists (e.g., eurytopy; Wood and Strait, 2004; Strait et al., 2013).

Nonetheless, some researchers maintain that hard foods were commonly consumed in Paranthropus, and/or played a significant role in the craniodental evolution of the genus (e.g., Constantino et al., 2009; Constantino et al., 2018; Paine et al., 2019; Strait et al., 2013; Smith et al., 2015). Chipping is usually one of the main forms of evidence proposed to support these hypotheses, typically to show that hard object consumption was common (Constantino et al., 2010, Constantino et al., 2018; Ungar, 2019; Paine et al., 2019). Earlier work suggested that ingestion of grit or bones may instead be responsible for the chipping in their teeth (Robinson, 1954; Tobias, 1967). 
Despite being crucial in elucidating the evolution and diet of Paranthropus, a broad comparison specifically focusing on chipping patterns in Paranthropus relative to other hominins and extant primates is still lacking. In particular, although data in the current article comes from published sources, because Paranthropus was not the focus of these studies, it has led to misunderstandings of interpretation. For example, Paine et al. (2019:104) stated that P. robustus had a "significant degree of hard object feeding," with Towle et al. (2017) cited to support this claim. In reality, Towle et al. (2017) reported that $P$. robustus has the lowest rate of chipping of any hominin studied, with a prevalence similar to gorillas. Additionally, in previous studies Paranthropus species are often only compared to one another, or to other fossil hominins. For example, the $P$. robustus diet is said to have contained a "significant amount of hard food content," based on higher chipping prevalence than in P. boisei (Constantino et al., 2018:76). Therefore, chipping is often considered evidence of regular hard food consumption, but extant comparisons are needed to determine if these conclusions are supported in primates that are known hard-object feeders.

In three recent studies that include comparisons of chipping in a total of 25 extant primate species (Towle and Loch, 2021; Fannin et al., 2020; Towle et al., 2017), all samples show at least some chips. Therefore, the presence of chipping in a sample on its own may tell us little about diet or behavior. Instead, the evaluation of the patterns in extant primates with associated ecological data allows an understanding of chipping relative to diet and behavior. In this study, we compared these patterns in a range of extant primates and fossil hominins, to test whether prevalence and patterns in Paranthropus support habitual, or occasional, durophagy. The extant primates analyzed include several species considered hard-object feeding specialists (sooty mangabeys, mandrills and sakis). Other species either focus on particular non-hard food items or have been reported to rarely consume hard foods (including several ape and colobus species), and those with a more varied diet, including eurytopy and terrestrial species (e.g., Japanese macaques, mandrills and baboons). As well as prevalence, the size and distribution of chips across the dentition when compared to other species may help elucidate behavioral factors that led to their occurrence in Paranthropus.

\section{Materials and Methods}


Data were compiled from the recent literature. Fossil hominin samples include specimens assigned to Homo naledi, Australopithecus africanus, P. robustus, P. boisei, and H., neanderthalensis (following Towle et al., 2017; Constantino et al., 2018; Constantino and Lawn, 2019; Belcastro et al., 2018). Extant primates include chimpanzees (Pan troglodytes troglodytes), Western lowland gorillas (Gorilla gorilla gorilla), Kloss's gibbons (Hylobates klossii), hamadryas baboons (Papio hamadryas), pig-tailed langurs (Simias concolor), Japanese macaques (Macaca fuscata), Dent's mona monkeys (Cercopithecus denti), blue monkeys (Cercopithecus mitis), mandrills (Mandrillus leucophaeus and M. sphinx), Raffles' banded langurs (Presbytis femoralis), Mentawai langurs (P. potenziani), and brown woolly monkeys (Lagothrix lagothricha), Sakis (Pithecia sp.), sooty mangabeys (Cercocebus atys), olive colobus monkeys (Procolobus verus), Western red colobus (Piliocolobus badius) and king colobus (Colobus polykomos; following Towle and Loch, 2021; Towle et al., 2017; Fannin et al., 2020). In these studies, data collection methods were standardized, with only minor variations in techniques. An exception is Fannin et al. (2020), where only fourth premolars and first molars were studied. A summary of methods is given below.

Some hominin species, particularly $P$. robustus and $A$. africanus, were studied previously for chipping prevalence (e.g., Grine et al., 2010; Robinson, 1956; Wallace, 1973; Tobias, 1967). Here, data from Towle et al. (2017) are used for these species. Teeth with minimal wear were removed for prevalence in Towle et al., (2017), but are included here to allow direct comparisons with other samples, resulting in slightly different frequencies than before.

Antemortem fractures were only recorded if subsequent attrition is evident on the chipped surface (i.e., the chip scar), to rule out postmortem damage (Scott and Winn, 2011; Belcastro et al., 2018). Smoothing and coloration were used for this purpose, i.e., postmortem fractures displaying 'fresh' enamel brighter than the rest of the crown and with sharp edges (Towle and Loch, 2021). The total number of chips on each tooth was also recorded for some samples (Belcastro et al., 2018; Towle et al., 2017; Towle and Loch, 2021). Results refer to all permanent teeth unless stated otherwise.

Fractures were recorded on a three-point grading system following either Bonfiglioli et al. (2004) or Towle and Loch (2021). The latter uses slight modifications that remove direct measurements to allow a broader range of comparisons among primates: 
(1) Small enamel chip (crescent-shaped) on the outer edge of the enamel. Dentine is not exposed and the chip is restricted to the outer rim of the occlusal surface.

(2) Larger chip that extends near to the enamel-dentine junction. A small area of dentine might be exposed.

(3) Large irregular fracture in which a significant area of dentine is exposed. More dentine than enamel was removed by the fracture.

\section{Results}

Prevalence and overall patterns of permanent tooth chipping for each species with comparable data are summarized in Table 1. Hominins cover the range of prevalence in extant primates, with chipping common in Homo (37-45\% of all permanent teeth) and rare in Paranthropus (4-11\%). Australopithecus africanus falls between these two extremes with $17 \%$ of teeth displaying at least one fracture. The prevalence in Paranthropus is similar to the extant ape species studied, chimpanzees, gibbons and gorillas (Table 1). The chipping rate in extant primates considered to be hard-food specialists (e.g., sakis and mandrills, $28 \%$ and $37 \%$ respectively) is several times greater than in both Paranthropus species (P. boisei, 4.4\%; P. robustus, $11.1 \%$; Table 1 ).

Further direct comparisons are made with additional species from Fannin et al. (2020) for first molars and fourth premolars in Figure 1, with P. robustus displaying the fourth lowest rate of fractures out of 20 species studied. Further, this equates to a chipping prevalence for these teeth approximately five times fewer than both Sooty mangabey and $H$. naledi (Figure 1). When split into individual tooth types, all $P$. robustus teeth show consistently low chipping rates, except for canines and third premolars, with a moderate prevalence ( $21 \%$ and $23 \%$ respectively). Each P. robustus molar type (first, second and third) shows a low prevalence of chipping, with each displaying one of the lowest rates relative to the same tooth in other species (Table 2). Few P. robustus teeth exhibit multiple chips $(6.7 \%$ of chipped teeth have more than one fracture). Paranthropus robustus also has a high ratio of larger chips relative to most other species (1.7 small chip for every large fracture); only chimpanzees, gibbons and Neanderthals have similar proportions of large chips $(2.3,1.9$ and 0.9 small for every large fracture, respectively). When split into tooth categories, large chips were more frequent on anterior teeth and premolars in P. robustus, with molars showing a low rate of larger fractures similar to other species (Table 3). 


\section{Discussion and conclusions}

Chipping prevalence in extant primates links well with dietary and behavioral observations. Hard object-feeding primates have a high prevalence of tooth chipping (Towle and Loch, 2021; Fannin et al., 2020). Species considered hard-object feeding specialists have a prevalence $>25 \%$, with the diets of sooty mangabeys, mandrills and sakis containing significant amounts of hard foods (e.g., durophagy; Kinzey and Norconk, 1993; Fleagle and McGraw, 1999; McGraw et al., 2011; Pampush et al., 2013; Fannin et al., 2020; vanCasteren et al., 2020). The overall chipping prevalence in both Paranthropus species is far below this threshold (4-11\%). Furthermore, the prevalence in first molars and fourth premolars (for which most data is currently available) shows $P$. robustus with one of the lowest chipping rates.

Based on these results, the current study indicates that both Paranthropus species experienced significantly fewer crown chips than other hominin species, and several times less than extant primates consuming hard objects (e.g., food items and/or grit). The chipping prevalence in Paranthropus is similar to species that rarely masticate hard items, including several apes, colobines, and guenons. The findings do not corroborate that either Paranthropus species were habitual hard-object feeders, at least to the extent of modern durophagous primates such as sakis, mandrills, and sooty mangabeys. Daegling et al., (2013) suggested that the large posterior teeth of Paranthropus showed a greater prevalence of chips due to greater surface area. Crown fractures are also more likely to form on teeth with enamel defects or unusual wear (Soukup, 2019). The pitting enamel hypoplasia present on a large proportion of Paranthropus molars (Towle and Irish, 2019) suggests they may have been more fracture prone. Thus, durophagy may have been even less frequent than the low chipping rate in both Paranthropus species suggests. The low rate of multiple chips on a single tooth supports this conclusion.

There are other factors that influence chipping prevalence. In humans, chips are generally more common on anterior teeth due to food processing, trauma, or nonmasticatory cultural behavior, but frequencies vary substantially among groups (Scott and Winn, 2011; Stojanowski et al., 2015; Bonfiglioli et al., 2004; Gould, 1968; Larsen, 2015; Lous, 1970; Molnar et al., 1972). Grit is also masticated by many primates, and likely influences chipping rates in certain species (e.g., Van Casteren et al., 2019; Fannin et al., 
2020; Towle et al., 2017). Both of these factors are associated with an increase in chipping frequency. Therefore, a low rate of chipping in Paranthropus likely suggests that trauma related to both food consumption and other factors such as grit mastication were rare.

A possible exception is the moderate rate of large fractures on canines and third premolars, which may suggest a modest level of trauma in these regions. The average size of these fractures is similar to those on Neanderthal anterior teeth (Belcastro et al., 2018). However, a low rate of chipping on $P$. robustus incisors suggests a non-masticatory explanation is unlikely. Similarly, grit tends to create smaller fractures, which are more evenly distributed over the posterior dentition (Towle et al., 2017); thus, grit is also an unlikely cause for chipping in $P$. robustus. One possible explanation could be specific masticatory behaviors, such as placing hard foods in these positions for the initial phase of mastication (e.g., breaking seeds or nuts). That said, the small sample size for individual tooth types makes inferences difficult, and the chipping rate is still only moderate when compared to other species. Therefore, although it is possible that $P$. robustus did occasionally masticate hard foods, there is little evidence to suggest this was a common practice.

Constantino et al. (2018) reported a rate of $5 \%$ chipping for $P$. robustus, which is similar to a more recent finding of $4.4 \%$ of teeth in P. boisei (Constantino and Lawn, 2019). The difference in prevalence for $P$. robustus in Towle et al. (2017) likely relates to stricter criteria for inclusion in the former study (i.e., deciduous and postmortem damaged teeth were removed from analysis), with both studies recording approximately 30 chipped teeth. If all teeth are included from the Towle et al (2017) data set (i.e., including postmortem damaged teeth) there is a more similar chipping rate of $7.46 \%$. Therefore, the chipping prevalence in Paranthropus seems consistently low across studies when compared to other primates, and the actual chipping prevalence between Paranthropus species is likely similar.

It has been suggested that Paranthropus preferred soft or tough foods, but relied on harder foods as 'fallback foods' (Constantino and Wright, 2009; Ungar et al., 2008). This hypothesis suggests Paranthropus evolved large teeth and robust cranial structures to cope with dietary items that were rarely consumed, but required requisite adaptations. This hypothesis has been challenged, with other scenarios favored (Daegling et al., 2013; Scott et al., 2014). Extant primate chipping patterns may offer some insight. Species that evolved specialized dental characteristics for softer foods can still occasionally eat hard foods (e.g., 
van Casteren et al., 2019). Additionally, an occasional hard object-feeding primate (consumed as seasonal or as fallback foods) can show elevated chipping frequencies. For example, while the diet of brown woolly monkeys is primarily based on soft fruits, at certain times of the year they consume seeds and hard fruits (Peres, 1994; Defler and Defler, 1996); this dietary shift could explain their relatively high chipping prevalence, although further research is needed into the mechanical properties of these foods.

The orientation of the hard object and underlying enamel microstructure is crucial in chip formation, as are the size and shape of the tooth, the object, and resultant biomechanical forces (Xu et al., 1998; Lucas et al., 2008; Chai and Lawn, 2007). As such, species-specific enamel attributes (e.g., thickness and mechanical properties) likely evolved for functional reasons (Cuy et al., 2002); species that regularly eat hard foods likely evolved dental characteristics in response to high biomechanical demands (Ungar and Lucas, 2010). It has been suggested that thick enamel may have evolved in some hominins, including Paranthropus, to delay fracture-related tooth loss (Kay, 1981; Lucas et al., 2008). Although chipping cannot conclusively be used to infer whether thick enamel in Paranthropus evolved to counter attrition or fracture, it seems chipping should not be used to support the hypothesis that thick enamel evolved to protect against fracture in Paranthropus. This is especially the case since molars are often the focus of such research, and in P. robustus a low chipping prevalence is evident in molars.

Other enamel characteristics also need to be considered with microstructure (e.g., Hunter-Schreger band thickness and enamel prism density) and overall tooth morphology potentially contributing to reduce fracture or limit chip size (Constantino et al., 2009). Further comparative studies can elucidate the functional and evolutionary implications of enamel structure in Paranthropus. The present study suggests that dental chipping in Paranthropus was rare relative to other hominins and extant durophagous primates. The ability of such enamel chips to deduce the selective pressures influencing the Paranthropines' unique craniofacial hypodigm remains opaque. Additionally, differences in tooth properties among species, and how these differences influence fracture likelihood, need to be more adequately explored. Future work is needed to determine the causal factors for the low chipping frequency in paranthropines. However, based on extant primate 
comparisons, these chips should not be used as evidence to suggest Paranthropus regularly masticated hard foods.

\section{Acknowledgements}

Research was supported by a Sir Thomas Kay Sidey Postdoctoral fellowship from the University of Otago to IT. We acknowledge Luke D. Fannin for helpful comments and suggestions on the manuscript. We also give thanks to the reviewers, associate editor, and co-editor-in-chief, whose comments greatly improved the manuscript.

\section{References}

Belcastro, M. G., Mariotti, V., Riga, A., Bonfiglioli, B., Frayer, D. W. 2018. Tooth fractures in the Krapina Neandertals. J. Hum. Evol. 123, 96-108.

Beynon, A. D., Wood, B. A. 1986. Variations in enamel thickness and structure in East African hominids. Am. J. Phys. Anthropol. 70, 177-193.

Cerling, T. E., Mbua, E., Kirera, F. M., Manthi, F. K., Grine, F. E., Leakey, M. G., Sponheimer, M., Uno, K. T. 2011. Diet of Paranthropus boisei in the early Pleistocene of East Africa. Proc. Natl. Acad. Sci. USA 108, 9337-9341.

Cofran, Z. 2014. Mandibular development in Australopithecus robustus. Am. J. Phys. Anthropol. 154, 436-446.

Constantino, P. J., Lawn, B. R. 2019. Dental fracture mechanics: What broken teeth can reveal about diet and feeding behavior. Am. J. Phys. Anthropol. 168, 47-48.

Constantino, P. J., Wright, B. W. 2009. The importance of fallback foods in primate ecology and evolution. Am. J. Phys. Anthropol. 140, 599-602.

Constantino, P. J., Borrero-Lopez, O., Lawn, B. R. 2018. Mechanisms of tooth damage and Paranthropus dietary reconstruction. Biosurf. Biotribol. 4, 73-78.

Constantino, P. J., Lucas, P. W., Lee, J. J. W., Lawn, B. R. 2009. The influence of fallback foods on great ape tooth enamel. Am. J. Phys. Anthropol. 140, 653-660. 
Daegling, D. J., Judex, S., Ozcivici, E., Ravosa, M. J., Taylor, A. B., Grine, F. E., Teaford, M. F., Ungar, P. S. 2013. Viewpoints: Feeding mechanics, diet, and dietary adaptations in early hominins. Am. J. Phys. Anthropol. 151, 356-371.

Defler, T. R., Defler, S. B. 1996. Diet of a group of Lagothrix Lagothricha Lagothricha in southeastern Colombia. Int. J. Primatol. 17(2), 161-190.

Dominy, N. J., Vogel, E. R., Yeakel, J. D., Constantino, P., Lucas, P. W. 2008. Mechanical properties of plant underground storage organs and implications for dietary models of early hominins. Evolutionary Biology, 35(3), 159-175.

Dominy, N. J. 2012. Hominins living on the sedge. Proc. Natl. Acad. Sci. USA 109.50 (2012): 20171-20172.

Fannin, L. D., Guatelli-Steinberg, D., Geissler, E., Morse, P. E., Constantino, P. J., McGraw, W. S. 2020. Enamel chipping in Taï Forest cercopithecids: Implications for diet reconstruction in paleoanthropological contexts. J. Hum. Evol. 141, 102742.

Fleagle, J. G., McGraw, W. S. 1999. Skeletal and dental morphology supports diphyletic origin of baboons and mandrills. Proc. Natl. Acad. Sci. USA 96(3), 1157-1161.

Gao, S. S., An, B. B., Yahyazadehfar, M., Zhang, D., Arola, D. D. 2016. Contact fatigue of human enamel: Experiments, mechanisms and modeling. Journal of The Mechanical Behavior of Biomedical Materials, 60, 438-450.

Grine, F. E., Daegling, D. J. 2017. Functional morphology, biomechanics and the retrodiction of early hominin diets. Comptes Rendus Palevol, 16(5-6), 613-631.

Grine, F. E., Ungar, P. S., Teaford, M. F., El-Zaatari, S. 2006. Molar microwear in Praeanthropus afarensis: evidence for dietary stasis through time and under diverse paleoecological conditions. J. Hum. Evol. 51(3), 297-319.

Grine, F. E., Judex, S., Daegling, D. J., Ozcivici, E., Ungar, P. S., Teaford, M. F., Sponheimer, M., Scott, J., Scott, R.S., Walker, A. 2010. Craniofacial biomechanics and functional and dietary inferences in hominin paleontology. J. Hum. Evol. 58(4), 293-308.

Guatelli-Steinberg, D. 2016. What teeth reveal about human evolution. Cambridge, Cambridge University Press. 
Jolly, C. J. 1970. The seed-eaters: a new model of hominid differentiation based on a baboon analogy. Man, 5(1), 5-26

Kaiser, T. M., Marce-Nogue, J., Puschel, T. A., Daasch, A. 2019. Morpho-functional traits of the mandible suggest no hard food adaptation in the hominin lineage. In Am. J. Phys. Anthropol. 168, 118-118.

Kinzey, W. G., Norconk, M. A. 1993. Physical and chemical properties of fruit and seeds eaten by Pithecia and Chiropotes in Surinam and Venezuela. International Journal of Primatology, 14, 207-227.

Laden, G., Wrangham, R. 2005. The rise of the hominids as an adaptive shift in fallback foods: plant underground storage organs (USOs) and australopith origins. J. Hum. Evol. 49, 482-498.

Lucas, P. W., Gaskins, J. T., Lowrey, T. K., Harrison, M. E., Morrogh-Bernard, H. C., Cheyne, S. M., Begley, M. R. 2012. Evolutionary optimization of material properties of a tropical seed. J. R. Soc. Interface 9, 34-42.

Macho, G. A., Shimizu, D. 2009. Dietary adaptations of South African australopiths: Inference from enamel prism attitude. J. Hum. Evol. 57, 241-247.

Macho, G. A. 2014. Baboon feeding ecology informs the dietary niche of Paranthropus boisei. PLoS One, 9, e84942.

Marcé-Nogué, J., Püschel, T.A., Daasch, A., Kaiser, T.M. 2020. Broad-scale morpho-functional traits of the mandible suggest no hard food adaptation in the hominin lineage. Sci. Rep. 10, 6793. https://doi.org/10.1038/s41598-020-63739-5

Martínez, L. M., Estebaranz-Sánchez, F., Galbany, J., Pérez-Pérez, A. 2016. Testing dietary hypotheses of East African hominines using buccal dental microwear data. PloS one, 11, e0165447.

McGraw, W. S., Vick, A. E., Daegling, D. J. 2011. Sex and age differences in the diet and ingestive behaviors of sooty mangabeys (Cercocebus atys) in the Tai Forest, Ivory Coast. Am. J. Phys. Anthropol. 144, 140-153. 
Nystrom, P., Phillips-Conroy, J. E., Jolly, C. J. 2004. Dental microwear in anubis and hybrid baboons (Papio hamadryas, sensu lato) living in Awash National Park, Ethiopia. Am. J. Phys. Anthropol. 125, 279-291.

Paine, O. C., Koppa, A., Henry, A. G., Leichliter, J. N., Codron, D., Codron, J., Lambert, J.E., Sponheimer, M. 2019. Seasonal and habitat effects on the nutritional properties of savanna vegetation: Potential implications for early hominin dietary ecology. J. Hum. Evol. 133, 99107.

Pampush, J. D., Duque, A. C., Burrows, B. R., Daegling, D. J., Kenney, W. F., McGraw, W. S. 2013. Homoplasy and thick enamel in primates. J. Hum. Evol, 64(3), 216-224.

Peres, C. A. 1994. Diet and feeding ecology of gray woolly monkeys (Lagothrix lagotricha cana) in central Amazonia: Comparisons with other atelines. Int. J. Primatol. 15, 333-372.

Peterson, A., Abella, E. F., Grine, F. E., Teaford, M. F., Ungar, P. S. 2018. Microwear textures of Australopithecus africanus and Paranthropus robustus molars in relation to paleoenvironment and diet. J. Hum. Evol. 119, 42-63.

Rabenold, D., Pearson, O. M. 2011. Abrasive, silica phytoliths and the evolution of thick molar enamel in primates, with implications for the diet of Paranthropus boisei. PLoS One, 6, e28379.

Rak Y. 1983. The Australopithecine Face. New York, Academic Press.

Richmond, B. G., Green, D. J., Lague, M. R., Chirchir, H., Behrensmeyer, A. K., Bobe, R., Bamford, M.K., Griffin, N.L., Gunz, P., Mbua, E., Merritt, S. R. 2020. The upper limb of Paranthropus boisei from Ileret, Kenya. J. Hum. Evol. 141, 102727.

Robinson, J.T., 1956. The Dentition of the Australopithecinae. Transvaal Museum Memoir, 9. Transvaal Museum, Pretoria

Rosenberger, A. L., Strier, K. B. 1989. Adaptive radiation of the ateline primates. J. Hum. Evol. 18, 717-750.

Sanchez-Gonzalez, E., Pinilla-Cienfuegos, E., Borrero-Lopez, O., Rodríguez-Rojas, F., Guiberteau, F. 2020. Contact damage of human dental enamel under cyclic axial loading with abrasive particles. J. Mech. Behav. Biomed. Mater. 102, 103512. 
Scott, J. E., Campbell, R. M., Baj, L. M., Burns, M. C., Price, M. S., Sykes, J. D., Vinyard, C. J. 2018. Dietary signals in the premolar dentition of primates. J. Hum. Evol. 121, 221-234.

Scott, J. E., McAbee, K. R., Eastman, M. M., Ravosa, M. J. 2014. Experimental perspective on fallback foods and dietary adaptations in early hominins. Biol. Lett. 10, 20130789.

Scott, R. S., Ungar, P. S., Bergstrom, T. S., Brown, C. A., Grine, F. E., Teaford, M. F., Walker, A. 2005. Dental microwear texture analysis shows within-species diet variability in fossil hominins. Nature 436, 693-695.

Sender, R. S., Hilko, A. S., Schwartz, G. T., Strait, D. S. 2020. Biomechanical implications of variation in Hunter-Schreger Bands in early hominins. Am. J. Phys. Anthropol. 171, 258-258.

Smith, A. L., Benazzi, S., Ledogar, J. A., Tamvada, K., Pryor Smith, L. C., Weber, G. W., Spencer, M.A., Lucas, P.W., Michael, S., Shekeban, A., I-Fadhalah, K. 2015. The feeding biomechanics and dietary ecology of Paranthropus boisei. Anat. Rec. 298, 145-167.

Soukup, J., 2019. Traumatic Dentoalveolar Injuries. In: Lobprise, H.B., Dodd, J.R. (Eds.), Wigg's Veterinary Dentistry Principles and Practice. Lippincott, New York, pp. 109e130.

Sponheimer, M., Passey, B. H., De Ruiter, D. J., Guatelli-Steinberg, D., Cerling, T. E., LeeThorp, J. A. 2006. Isotopic evidence for dietary variability in the early hominin Paranthropus robustus. Science $314,980-982$.

Strait, D. S., Constantino, P., Lucas, P. W., Richmond, B. G., Spencer, M. A., Dechow, P. C., Ross, C.F., Grosse, I.R., Wright, B.W., Wood, B.A., Weber, G. W. 2013. Viewpoints: Diet and dietary adaptations in early hominins: The hard food perspective. Am. J. Phys. Anthropol. $151,339-355$.

Teaford MF, Ungar PS. 2000. Diet and the evolution of the earliest human ancestors. Proc. Natl. Acad. Sci. USA 97, 506-13 511.

Teaford, M. F., Ungar, P. S., Taylor, A. B., Ross, C. F., Vinyard, C. J. 2020. The dental microwear of hard-object feeding in laboratory Sapajus apella and its implications for dental microwear formation. Am. J. Phys. Anthropol. 171, 439-455.

Thiery, G., Lazzari, V., Ramdarshan, A., Guy, F. 2017. Beyond the map: Enamel distribution characterized from 3D dental topography. Front. Physiol. 8, 524. 
Tobias, P.V., 1967. The Cranium of Australopithecus (Zinjanthropus) boisei. Olduva iGorge, vol. 2. Cambridge University Press, Cambridge.

Towle, I., Irish, J. D. 2019. A probable genetic origin for pitting enamel hypoplasia on the molars of Paranthropus robustus. J. Hum. Evol. 129, 54-61.

Towle, I., Irish, J. D., De Groote, I. 2017. Behavioral inferences from the high levels of dental chipping in Homo naledi. Am. J. Phys. Anthropol. 164, 184-192.

Towle, I., Loch, C., Irish, J. D., Veneziano, A., Ito, T. 2021. Chipping and wear patterns in extant primate and fossil hominin molars: 'Functional' cusps are associated with extensive wear but low levels of fracture. J. Hum. Evol. 151, 102923. DOI: 10.1016/j.jhevol.2020.102923

Towle, I., Loch, C. 2021. Tooth chipping prevalence and patterns in extant primates. Am. J. Phys. Anthropol. 1- 8. DOI: https://doi.org/10.1002/ajpa.24232

Ungar PS, Grine FE, Teaford MF. 2008. Dental microwear and diet of the Plio-Pleistocene hominin Paranthropus boisei. PLoS One, 3, e2044.

Ungar PS, Scott RS, Grine FE, Teaford MF. 2010. Molar microwear textures and the diets of Australopithecus anamensis and Australopithecus afarensis. Philos. Trans. R. Soc. Lond. 365, 3345-3354.

Ungar, P. S. 2019. Inference of diets of early hominins from primate molar form and microwear. J. Den. Res. 98, 398-405.

Ungar, P. S., Hlusko, L. J. 2016. The evolutionary path of least resistance. Science, 353, 29-30. Ungar, P. S., Lucas, P. W. 2010. Tooth form and function in biological anthropology. In: Larsen, C.S. (Ed.), A companion to Biological Anthropology. Wiley-Blackwell, Malden, pp. $516-529$.

van Casteren, A., Strait, D. S., Swain, M. V., Michael, S., Thai, L. A., Philip, S. M., Saji, S., AlFadhalah, K., Almusallam, A.S., Shekeban, A., McGraw, W. S. 2020. Hard plant tissues do not contribute meaningfully to dental microwear: Evolutionary implications. Sci. Rep. 10, 582. https://doi.org/10.1038/s41598-019-57403-w 
van Casteren, A., Wright, E., Kupczik, K., Robbins, M. M. 2019. Unexpected hard-object feeding in Western lowland gorillas. Am. J. Phys. Anthropol. 170, 433-438.

Van der Merwe, N. J., Masao, F. T., Bamford, M. K. 2008. Isotopic evidence for contrasting diets of early hominins Homo habilis and Australopithecus boisei of Tanzania. S. Afri. J. Sci. $104,153-155$.

Vogel, E. R., van Woerden, J. T., Lucas, P. W., Atmoko, S. S. U., van Schaik, C. P., Dominy, N. J. 2008. Functional ecology and evolution of hominoid molar enamel thickness: Pan troglodytes schweinfurthii and Pongo pygmaeus wurmbii. J. Hum. Evol. 55, 60-74.

Wallace, J.A., 1973. Tooth chipping in the australopithecines. Nature 244, 117-118.

Williams, F. L. E. 2015. Dietary proclivities of Paranthropus robustus from Swartkrans, South Africa. Anthropol. Rev. 78, 1-19.

Wood, B., Strait, D. 2004. Patterns of resource use in early Homo and Paranthropus. J. Hum. Evol. 46, 119-162.

Yeakel, J. D., Bennett, N. C., Koch, P. L., Dominy, N. J. 2007. The isotopic ecology of African mole rats informs hypotheses on the evolution of human diet. Proc. R. Soc. B. 274, 17231730.

\section{Figures and Tables}




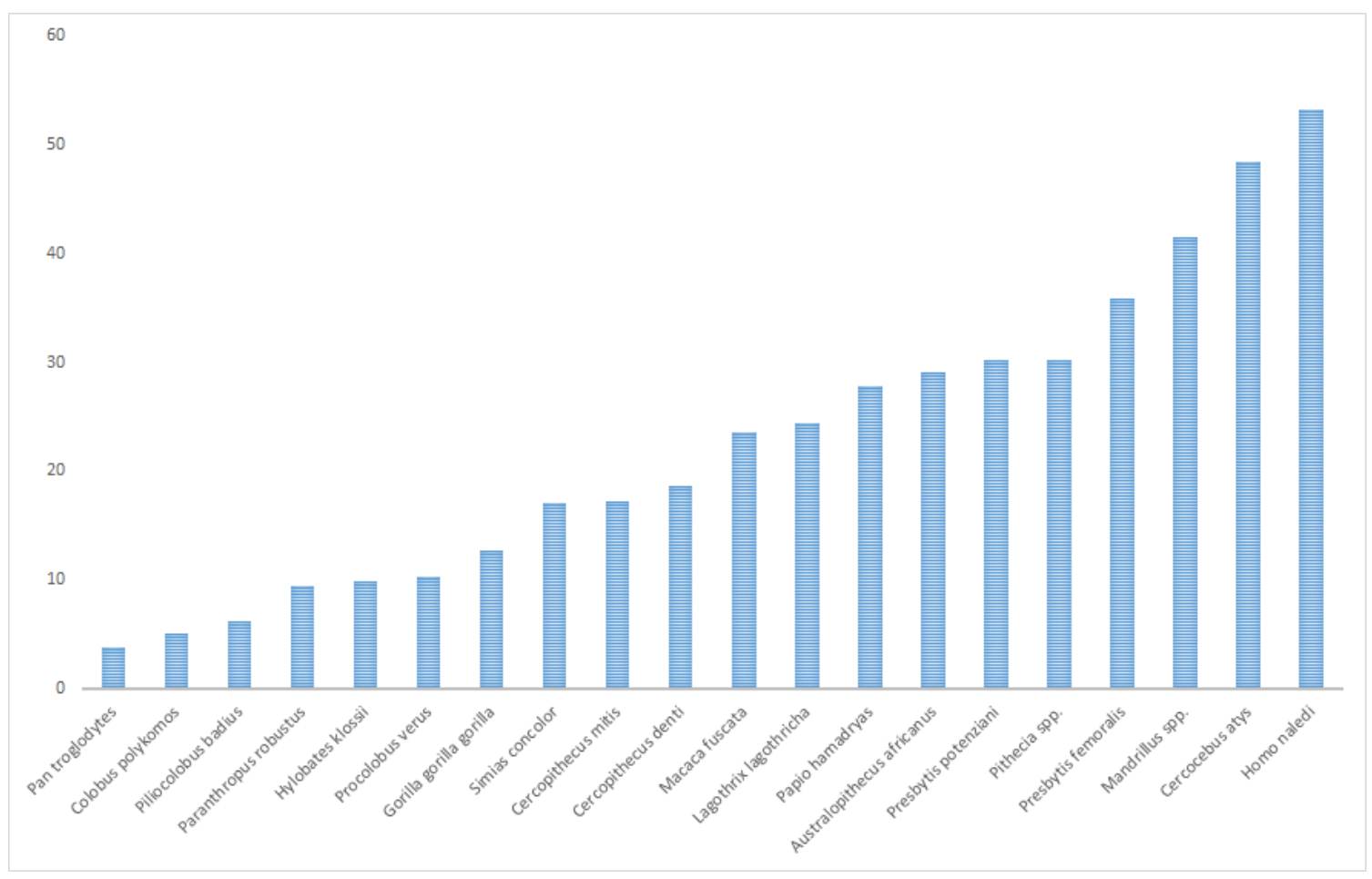

Figure 1. Chipping prevalence for first molars and fourth premolars for different extant primate and fossil hominin species. Species are organized by increasing chipping prevalence. 


\section{Table 1}

Prevalence of chipping in different primate species, by tooth type, jaw, and size of chips. Data refers to all permanent teeth unless stated.

\begin{tabular}{|c|c|c|c|c|c|c|c|}
\hline Species & Common name & Posterior teeth & Anterior teeth & All teeth \% & $\begin{array}{l}\text { Multiple } \\
\text { chipped teeth \% }\end{array}$ & $\begin{array}{l}\text { Small:large } \\
\text { chip ratio }\end{array}$ & Reference \\
\hline Homo naledi & & $46.39(45 / 97)$ & $20.75(11 / 53)$ & $37.33(56 / 150)$ & 50.00 & 8.33 & Towle et al. (2017) \\
\hline Australopithecus africanus & & $20.16(50 / 248)$ & $7.32(6 / 82)$ & $16.97(56 / 330)$ & 16.07 & 10.20 & Towle et al. (2017) \\
\hline Paranthropus robustus & & $10.90(23 / 211)$ & $11.86(7 / 59)$ & $11.11(30 / 270)$ & 6.67 & 1.73 & Towle et al. (2017) \\
\hline Paranthropus boise $i^{\mathrm{a}}$ & & - & - & $4.4^{\mathrm{b}}$ & - & - & Constantino and Lawn (2019) \\
\hline Homo neanderthalensis & Neanderthals & $31.53(35 / 111)$ & $64.86(48 / 74)$ & $44.86(83 / 185)$ & 9.00 & 0.90 & Belcastro et al. (2018) \\
\hline Gorilla gorilla gorilla & Western lowland gorilla & $11.70(137 / 1171)$ & $5.25(32 / 610)$ & $9.49(169 / 1781)$ & 4.14 & 10.27 & Towle et al. (2017) \\
\hline Pan troglodytes & Chimpanzee & $4.52(65 / 1439)$ & $4.13(33 / 800)$ & $4.38(98 / 2239)$ & 2.04 & 2.27 & Towle et al. (2017) \\
\hline Cercopithecus denti & Dent's mona monkey & $16.11(29 / 180)$ & $27.06(23 / 85)$ & $19.62(52 / 265)$ & 1.92 & 5.50 & Towle and Loch (2021) \\
\hline Cercopithecus mitis & Blue monkey & $18.13(29 / 160)$ & $9.76(8 / 82)$ & $15.29(37 / 242)$ & 13.51 & 6.40 & Towle and Loch (2021) \\
\hline Mandrillus spp. & Mandrill & $36.11(39 / 108)$ & $40.00(8 / 20)$ & $36.72(47 / 128)$ & 23.40 & 6.83 & Towle and Loch (2021) \\
\hline Presbytis femoralis & Raffles' banded langur & $31.88(51 / 160)$ & $40.24(33 / 82)$ & $34.71(84 / 242)$ & 11.90 & 4.60 & Towle and Loch (2021) \\
\hline Presbytis potenziani & Mentawai langur & $20.25(32 / 158)$ & $17.39(12 / 69)$ & $19.38(44 / 227)$ & 11.36 & 43.00 & Towle and Loch (2021) \\
\hline Hylobates klossii & Kloss's gibbon & $5.60(13 / 232)$ & $11.90(10 / 84)$ & $7.28(23 / 316)$ & 0.00 & 1.88 & Towle and Loch (2021) \\
\hline Simias concolor & Pig-tailed langur & $16.61(46 / 277)$ & $19.70(26 / 132)$ & $17.60(72 / 409)$ & 12.50 & 7.00 & Towle and Loch (2021) \\
\hline Lagothrix lagothricha & Brown woolly monkey & $21.79(34 / 156)$ & $11.27(8 / 71)$ & $18.50(42 / 227)$ & 0.00 & 7.40 & Towle and Loch (2021) \\
\hline Pithecia spp. & Saki & $35.09(60 / 171)$ & $11.59(8 / 69)$ & $28.33(68 / 240)$ & 23.53 & 5.80 & Towle and Loch (2021) \\
\hline Papio hamadryas & Hamadryas baboon & $26.49(89 / 336)$ & $9.89(18 / 182)$ & $20.66(107 / 518)$ & 8.41 & 7.23 & Towle and Loch (2021) \\
\hline
\end{tabular}

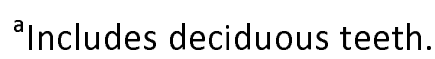

bSample size not provided. 


\section{Table 2}

Prevalence of chipping (\%) in different primate species, split by individual permanent tooth types. I: incisor; C: canine; PM: premolar; M: molar.

\begin{tabular}{|c|c|c|c|c|c|c|c|c|c|}
\hline Species & Common name & 11 & 12 & $\mathrm{C}$ & РM3 & PM4 & M1 & M2 & M3 \\
\hline $\begin{array}{l}\text { Homo naledi } \\
\text { Australopithecus }\end{array}$ & & $40(6 / 15)$ & $12.5(2 / 16)$ & $13.64(3 / 22)$ & $42.11(8 / 19)$ & $42.11(8 / 19)$ & $60.71(17 / 28)$ & $36.84(7 / 19)$ & $41.67(5 / 12)$ \\
\hline africanus & & $17.39(4 / 23)$ & $4.35(1 / 23)$ & $2.78(1 / 36)$ & $18.60(8 / 43)$ & $32.43(12 / 37)$ & $29.53(13 / 49)$ & $17.91(12 / 67)$ & $9.62(5 / 52)$ \\
\hline Paranthropus robustus & & $9.38(3 / 32)$ & $7.69(1 / 13)$ & $21.43(3 / 14)$ & $23.33(7 / 30)$ & $4.65(2 / 43)$ & $13.46(7 / 52)$ & $4.65(2 / 43)$ & $11.63(5 / 43)$ \\
\hline Gorilla gorilla gorilla & $\begin{array}{l}\text { Western lowland } \\
\text { gorilla }\end{array}$ & $4.05(9 / 222)$ & $\begin{array}{l}5.12 \\
(11 / 215) \\
4.06\end{array}$ & $\begin{array}{l}6.94 \\
(12 / 173) \\
5.79\end{array}$ & $3.76(8 / 213)$ & $9.26(20 / 216)$ & $\begin{array}{l}15.22 \\
(44 / 289)\end{array}$ & $\begin{array}{l}10.89 \\
(28 / 257)\end{array}$ & $\begin{array}{l}18.88 \\
(37 / 196) \\
10.62\end{array}$ \\
\hline Pan troglodytes & Chimpanzee & $\begin{array}{l}2.79(8 / 287) \\
38.71\end{array}$ & $(11 / 271)$ & $(14 / 242)$ & $2.22(6 / 270)$ & $1.87(5 / 268)$ & $5.18(20 / 386)$ & $3.46(10 / 289)$ & $(24 / 226)$ \\
\hline Cercopithecus denti & Dent's mona monkey & $(12 / 31)$ & $34.62(9 / 26)$ & $7.14(2 / 28)$ & $8.57(3 / 35)$ & $10.81(4 / 37)$ & $26.32(10 / 38)$ & $15.79(6 / 38)$ & $18.75(6 / 32)$ \\
\hline Cercopithecus mitis & Blue monkey & $17.86(5 / 28)$ & $4(1 / 25)$ & $6.90(2 / 29)$ & $3.13(1 / 32)$ & $15.63(5 / 32)$ & $18.75(6 / 32)$ & $25(8 / 32)$ & $28.13(9 / 32)$ \\
\hline Mandrillus spp. & Mandrill & $\begin{array}{l}55.56(5 / 9) \\
52.17\end{array}$ & $\begin{array}{l}50(3 / 6) \\
46.15\end{array}$ & $\begin{array}{l}0(0 / 5) \\
34.48\end{array}$ & $13.64(3 / 22)$ & $33.33(7 / 21)$ & $50(10 / 20)$ & $50(11 / 22)$ & $34.78(8 / 23)$ \\
\hline Presbytis femoralis & Raffles' banded langur & $(12 / 23)$ & $(12 / 26)$ & $(10 / 29)$ & $18.75(6 / 32)$ & $31.25(10 / 32)$ & $40.63(13 / 32)$ & $31.25(10 / 32)$ & $37.5(12 / 32)$ \\
\hline Presbytis potenziani & Mentawai langur & $18.18(4 / 22)$ & $22.22(6 / 27)$ & $10(2 / 20)$ & $6.45(2 / 31)$ & $31.25(10 / 32)$ & $29.03(9 / 31)$ & $31.25(10 / 32)$ & $3.13(1 / 32)$ \\
\hline Hylobates klossii & Kloss's gibbon & $\begin{array}{l}2.78(1 / 36) \\
22.62\end{array}$ & $\begin{array}{l}12.5(4 / 32) \\
16.28\end{array}$ & $\begin{array}{l}31.25(5 / 16) \\
9.40\end{array}$ & $\begin{array}{l}4.26(2 / 47) \\
17.91\end{array}$ & $\begin{array}{l}6.52(3 / 46) \\
18.66\end{array}$ & $\begin{array}{l}13.33(6 / 45) \\
27.92\end{array}$ & $\begin{array}{l}3.85(2 / 52) \\
25.17\end{array}$ & $\begin{array}{l}0(0 / 42) \\
33.59\end{array}$ \\
\hline Macaca fuscata & Japanese macaque & $\begin{array}{l}(19 / 84) \\
29.79\end{array}$ & $(14 / 86)$ & $(11 / 117)$ & $(24 / 134)$ & $(25 / 134)$ & $(43 / 154)$ & $(36 / 143)$ & $(43 / 128)$ \\
\hline Simias concolor & Pig-tailed langur & $(14 / 47)$ & $13.33(6 / 45)$ & $15(6 / 40)$ & $8.62(5 / 58)$ & $10.53(6 / 57)$ & $24.07(13 / 54)$ & $28.07(16 / 57)$ & $11.76(6 / 51)$ \\
\hline Lagothrix lagothricha & Brown woolly monkey & $10.53(2 / 19)$ & $11.11(3 / 27)$ & $15.79(3 / 19)$ & $15.38(4 / 26)$ & $25.93(7 / 27)$ & $22.22(4 / 18)$ & $22.22(6 / 27)$ & $33.33(6 / 18)$ \\
\hline Pithecia spp. & Saki & $13.33(2 / 15)$ & $16.67(4 / 24)$ & $8.70(2 / 23)$ & $26.67(8 / 30)$ & $24.14(7 / 29)$ & $37.5(9 / 24)$ & $44.44(12 / 27)$ & $50(13 / 26)$ \\
\hline Papio hamadryas & Hamadryas baboon & $8.47(5 / 59)$ & $9.68(6 / 62)$ & $11.48(7 / 61)$ & $15.87(10 / 63)$ & $17.65(12 / 68)$ & $37.5(27 / 72)$ & $37.68(26 / 69)$ & $21.88(14 / 64)$ \\
\hline
\end{tabular}




\section{Table 3}

Prevalence of large chips, split by tooth type. Number of large chips (severity 2 and 3 ) as a percentage of total chips.

\begin{tabular}{llllll}
\hline Species & Common name & Molars & Premolars & Canines & Incisors \\
\hline Paranthropus robustus & & $14.29(2 / 14)$ & $44.44(4 / 9)$ & $100(3 / 3)$ & $50(2 / 4)$ \\
Homo naledi & & $17.24(5 / 29)$ & $6.25(1 / 16)$ & $0(0 / 3)$ & $0(0 / 8)$ \\
Australopithecus africanus & & $6.67(2 / 30)$ & $10(2 / 20)$ & $100(1 / 1)$ & $0(0 / 5)$ \\
Gorilla gorilla gorilla & Western lowland gorilla & $7.34(8 / 109)$ & $10.71(3 / 28)$ & $0(0 / 12)$ & $20(4 / 20)$ \\
Chimpanzees & Chimpanzee & $35.19(19 / 54)$ & $27.27(3 / 11)$ & $42.86(6 / 14)$ & $10.53(2 / 19)$ \\
Cercopithecus denti & Dent's mona monkey & $22.73(5 / 22)$ & $0(0 / 7)$ & $0(0 / 2)$ & $14.29(3 / 21)$ \\
Cercopithecus mitis & Blue monkey & $8.70(2 / 23)$ & $33.33(2 / 6)$ & $0(0 / 2)$ & $16.67(1 / 6)$ \\
Mandrillus spp. & Mandrill & $17.24(5 / 29)$ & $10(1 / 10)$ & $\mathrm{n} / \mathrm{a}(0 / 0)$ & $0(0 / 8)$ \\
Presbytis femoralis & Raffles' banded langur & $8.57(3 / 35)$ & $37.5(6 / 16)$ & $30(3 / 10)$ & $12.5(3 / 24)$ \\
Presbytis potenziani & Mentawai langur & $5(1 / 20)$ & $0(0 / 12)$ & $0(0 / 2)$ & $0(0 / 10)$ \\
Hylobates klossii & Kloss's gibbon & $50(4 / 8)$ & $20(1 / 5)$ & $40(2 / 5)$ & $20(1 / 5)$ \\
Macaca fuscata & Japanese macaque & $22.13(27 / 122)$ & $2.04(1 / 49)$ & $18.18(2 / 11)$ & $3.03(1 / 33)$ \\
Simias concolor & Pig-tailed langur & $11.43(4 / 35)$ & $9.09(1 / 11)$ & $0(0 / 6)$ & $20(4 / 20)$ \\
Lagothrix lagothricha & Brown woolly monkey & $18.75(3 / 16)$ & $0(0 / 11)$ & $33.33(1 / 3)$ & $0(0 / 5)$ \\
Pithecia spp. & Saki & $8.82(3 / 34)$ & $26.67(4 / 15)$ & $0(0 / 2)$ & $0(0 / 6)$ \\
Papio hamadryas & Hamadryas baboon & $11.94(8 / 67)$ & $9.09(2 / 22)$ & $14.29(1 / 7)$ & $18.18(2 / 11)$ \\
\hline
\end{tabular}

